\title{
Sarah Kofman, Freud y lo femenino
}

\author{
Sarah Kofman, Freud and the feminine
}

Luisa Posada Kubissa

Recibido: 23/05/2018

Aceptado: 20/11/2018

\section{RESUMEN}

Este trabajo se propone rescatar a una pensadora contemporánea poco (re)conocida hoy, como fue Sarah Kofman y, en particular, atender a la relevancia de sus ajustes críticos con el discurso freudiano sobre la feminidad. Desde una innegable afinidad intelectual con el padre del psicoanálisis, esta pensadora analiza las quiebras de su discurso cuando se trata de conceptualizar la femineidad, que la discípula entiende y revisa en Freud no sólo como insuficiente, sino como expresión de un subtexto patriarcal presente ya en filósofos tan reconocidos como Rousseau o el propio Kant. A partir de aquí, se entrará a discutir si estas posiciones de Kofman pueden ser leídas o no en clave de un discurso crítico-feminista.

Palabras clave: Rousseau, Kant, feminidad, "envidia del pene".

\section{ABSTRACT}

This work aims to rescue a contemporary thinker not enough recognised today, as was Sarah Kofman, and in particular to focus on the relevance of her critical adjustments with the Freudian discourse on femininity. From an undeniable intellectual affinity with the father of psychoanalysis, this thinker analyzes the failures of his speech when it comes to conceptualizing femininity, which the disciple understands and revises in Freud not only as insufficient, but as an expression of a patriarchal subtext already present in philosophers as wellknown as Rousseau or Kant himself. From here, it will be discussed if these positions of Kofman can be read or not in the key of a critical-feminist discourse.

Keywords: Rousseau, Kant, femininity, "penis envy". 


\section{LO FEMENINO EN EL DISCURSO ROUSSEAUNIANO $Y$ KANTIANO}

\subsection{Crítica al concepto de feminidad en Rousseau}

Sarah Kofman dejó tras de sí una amplia producción filosófica y psicoanalítica en el trayecto de su vida hasta su suicidio con sesenta años en 1994, una producción que recorre estaciones de pensamiento tan relevantes como Rousseau, Kant, Nietzsche, Freud o Derrida. Según la interpretación de Steve Edwin, la vida y la obra de Kofman ponen de manifiesto hasta qué punto "las genealogías psíquica y social de su trauma son indisociables" (Edwin, 2002, 138), según el análisis que realiza en su trabajo sobre la relevancia del trauma de Kofman por la muerte de su padre en Auschwitz. Sin embargo, más allá de esta $\mathrm{u}$ otras lecturas coyunturales, lo cierto es que se trata de una pensadora mal o escasamente (re)conocida aun en nuestros días y que, salvo en el caso de algunos escasos especialistas, parece más bien condenada al olvido. No se trata de entrar aquí en un detallado recorrido por su biografía y su producción intelectual, sobre lo que ya contamos con alguna más exhaustiva publicación (Feyertag, 2014), sino que lo que se propone más bien es centrarnos en la lectura que ella misma realizó de la cuestión femenina en pensadores como Rousseau, Kant y, sobre todo, Freud. Y hacerlo, además, con el objetivo de plantear la pertinencia de las tesis de Kofman para una perspectiva crítico-feminista.

Kofman comparte con el feminismo francés de los 70 la marca profunda que $E l$ segundo sexo de Simone de Beauvoir va a suponer y, de hecho, afirma haberlo leído ya en 1953 con el asombro de encontrase ante un libro atrevido, de lectura casi secreta, que hablaba explícitamente de la sexualidad femenina. Pero, cuarenta años después, reconoce con ironía que su interés por el título de Beauvoir ha variado: “Yo lo he leído (El segundo sexo) en 1953, hace 40 años (...) En esa época me asombraba más «sexo» que «el segundo». Ahora es «el segundo» lo que me interesa “(Rodgers, 1998, p. 176). De entrada, esta declaración evidencia además que Kofman tuvo ya tempranamente una abierta inquietud por el feminismo. 
Podríamos señalar también que, vía Derrida, Kofman apuesta por una visión deconstructiva, radicalmente enfrentada a cualquier orientación naturalista o esencialista también a la hora de pensar lo femenino y lo masculino. Y aplica esa mirada deconstructiva a sus lecturas críticas sobre lo femenino en Rousseau (cuando se ocupa de Rousseau y las mujeres), en Kant (al hablar de "La economía del respeto: Kant y el respeto por las mujeres") y particularmente en Freud (de quien siempre se consideró discípula y al que dedicó su revisión crítica en El enigma de la mujer. ¿Con Freud o contra Freud?).

Tomando pie en la tesis de Beauvoir de que la mujer en la tradición de pensamiento ha sido heterodesignada y conceptualizada como "lo otro", Kofman elabora su propio discurso sobre algunos puntales de esa tradición, pero se separa de Beauvoir en más de un aspecto. Por ejemplo, Kofman no comparte la impugnación beauvoiriana de la maternidad como verdadera servidumbre de la mujer; antes bien, entiende que la mujer, en tanto que madre, vive la relación con el hijo/a para siempre como parte de su propio cuerpo. Y defiende que en pleno siglo $X X$ se ha superado ya por completo la enseñanza judeocristiana, que llevaba a valorar a las hijas por debajo de los hijos varones, y se va abriendo camino la práctica de la corresponsabilidad de la madre y el padre en la crianza y educación de estos (Rodgers, 1998, p. 183).

A juicio de Kofman, Beauvoir no ha solucionado el problema de qué sea la mujer, pues al categorizarla como "lo otro" de lo masculino, que se auto-arroga lo genéricamente humano, no ha contribuido a desestabilizar o a deconstruir la homogeneidad esencial con la que es pensada. Para Kofman no hay nada, así como "la mujer" a la que adscribir unas características que le serían esencialmente específicas. Y ello le lleva también a rechazar reclamaciones como la de una "escritura femenina", como lo propone por ejemplo desde el pensamiento de la diferencia sexual Hélene Cixóus: "hablar de una «escritura femenina» significa remitirse de nuevo a una esencia del hombre y una esencia de la mujer" (Ender, 1993, p. 1). Frente a estas enunciaciones de corte esencialista Kofman opone la tesis de una bisexualidad que originariamente nos compone a los seres humanos, siguiendo aquí las ideas freudianas. $Y$ tomando pie ahí, desecha la idea de que haya funciones "naturales" para cada sexo, como 
la maternidad para las mujeres, apostando por trascender la dualidad masculino-femenino en tanto que mero producto de una construcción psicosocial y cultural.

Para Kofman está claro que no cabe atribuir la razón al hombre y pretender una lógica distinta para la mujer: hombres y mujeres comparten la misma capacidad racional y, a partir de esta, lo que hay es una diversidad de diferencias individuales que no se puede reducir al esquema binario de género. De esta manera se aleja de la reivindicación beauvoiriana de igualdad de los sexos, para embarcarse en una visión que reclama la pluralidad genérica y que, adelantando lo que luego serán las posiciones de la filósofa norteamericana Judith Butler y de la teoría queer, defiende que la sexualidad puede ser vivida de múltiples formas que escapan al rígido encorsetamiento en el binarismo sexual. En este sentido, hay que entender que celebre que, en sus días, "se empieza a reconocer lentamente la transexualidad" (Rodgers, 1998, p. 186). Y que critique la visión igualitarista del feminismo, por cuanto entiende que esta puede conducir a un asimilacionismo a las normas y los valores dominantes, que son normas y valores masculinos.

Frente al constructivismo de Beauvoir - que afirma, como es sabido, que la mujer no nace sino que se hace-, Kofman opone una visión más psicoanalítica, por la cual devenir mujer no sólo depende de una construcción político-social, sino que también depende de los "Triebe", de los impulsos en el sentido freudiano, que no son objeto de elección ni de determinación social. Con ello, y contra sus propias afirmaciones, Kofman parece no entender el binarismo sexual sólo como construido, sino también como producto de una determinación psíquica.

Por otro lado, es interesante señalar que la lectura que Kofman hace del problema de las mujeres en Nietzsche ha sido celebrada positivamente, ya que "posibilitó fructíferos acercamientos a la cuestión de la mujer en Nietzsche alejando su pensamiento del estigma de misoginia". Y se ha interpretado que dicha lectura explica además el problema de la mujer en este pensador, ya que “desde otro ángulo de visión, prendido de un matiz psicoanalítico, Kofman 
sospecha que la imagen de su madre es la que más particularmente atrapa a Nietzsche ocasionando en él la manifiesta ambivalencia de sus sentimientos ante las mujeres" (Burgos, 2002, p. 149).

En parecida clave psicoanalítica, Kofman se acerca también al pensamiento de Rousseau en Rousseau y las mujeres: ahí, ya al inicio, interpreta que "Rousseau apela, como es sabido constante, e insistentemente a la naturaleza, a la buena madre naturaleza. En su nombre argumenta siempre. Cómo se identifica con su madre, que está muerta, en tanto le regaló la vida, cómo intenta tomar el lugar de quien no se puede reemplazar, volverle a dar la vida, en tanto que se convierte por su parte en mujer y madre; así se esfuerza, en lugar de hablar de la naturaleza, en hablar de la madre general, que también está más o menos muerta" (Kofman, 1986, p. 11).

Esta lectura en términos psicoanalíticos quiere desvelar el miedo rousseauniano al fantasma de la mujer-madre que puede fagocitarlo o desposeerlo de su masculinidad:

“La inquietud, que procura el placer masoquista, de ser castigado, de ser inmovilizado como una mujer y de ser poseído por mujeres, de ser ahogado cuando éstas se resisten a ser madres totalmente al servicio del hombre que aplican compasión y sensibilidad hacia él, de que fueran responsables de su muerte, de su degeneración, su perversión, su emasculación (Entmannung)" (Kofman, 1986, pp. 35).

Frente a ese terror, Kofman interpreta que el filósofo ginebrino sólo puede aferrase a su fantasía:

“a la imagen de una idealizada y divinizada buena madre, o más aún para construirla y para interiorizarla, una madre que sólo puede ser la mejor de todas las madres -incluso aunque casi lo hubiera ahogado en su tripa, le hubiera parido de todos modos como «enfermizo e insano»" (Kofman, 1986, pp. 35-36).

Cuando Rousseau se ocupa en su Emilio o de la educación (1979) de la relación entre los sexos y de cómo debe ser educada la compañera del ciudadano, en su 
capítulo V dedicado a Sofía, Kofman subraya cómo su discurso se pretende conforme al orden natural de las cosas y cómo, de este modo, se presenta como inscrito en una "teleología natural". Pero este discurso de lo natural, que justifica las desigualdades y la jerarquía entre los sexos, se mueve "en la línea del más tradicional discurso falocrático", por el cual la reclusión de las mujeres al ámbito privado-doméstico y su exclusión del ámbito político-público quiere hacer pasar el ejercicio de poder por un orden de naturaleza (1986, p. 14). Ese orden imprimiría en las mujeres las características propias de lo femenino, como el pudor, que hace que "cuanto más cerca están las mujeres del estado de naturaleza, más vergonzosas son" (Kofman, 1986, p. 23), o también como "la inclinación al ornamento, a los espejos, a las piezas de joyería (que) pertenece a la naturaleza femenina" (1986, p. 24).

La apelación insistente a la naturaleza en el pensamiento rousseauniano sobre la feminidad no es sino el reflejo de los impulsos del pensador ante el terror a ser devorado por la madre:

"La tesis defendida por Rousseau está siempre siendo anticipada por sus impulsos (Triebe), la voz de la naturaleza es también el eco de su naturaleza (...) La insistencia «teorética» sobre la movilidad y la actividad masculina no puede ser separada de los fantasmas de ser paralizado, encerrado, ahogado en la tripa materna" (Kofman, 1986, p. 28).

La operación de entronizar a la madre es una manera de protegerse de esta figura castradora, por lo que "poner a las mujeres en un trono significa también protegerse de su carencia de falo" (Kofman, 1986, p. 37)

La relectura que Kofman hace del pensamiento de Rousseau le permite realizar un acercamiento al pensamiento de Freud sobre la feminidad desde las mismas claves críticas. Por ello, al concluir su análisis de Rousseau, Kofman afirma que

“Gracias a nuestra lectura de Rousseau podemos apercibirnos de la más discreta apelación de Freud, que sólo persigue el rigor científico, en el que como es reconocible el recurso a la naturaleza o a las ciencias biológicas supone siempre un punto débil de su pensamiento y encubre 
una finalidad falocrática. Tanto si se es el autor de una «novela de formación», de un sistema filosófico o de una obra psicoanalítica con pretensión científica, nunca se es un sujeto transcendental y objetivo, sexualmente neutral" (Kofman, 1986, p. 39).

\subsection{Crítica al concepto de feminidad en Kant}

La Cuando Kofman se ocupa del pensamiento kantiano sobre las mujeres, su análisis sitúa el mismo en una concepción falocrática semejante a la de Rousseau. Kant habla del respeto por las mujeres (Kant, 1977) y Kofman se pregunta si ese respeto “¿consiste simplemente en obedecer el imperativo categórico que requiere respeto en consideración del otro como persona moral?" (2007, p. 187). Y su respuesta a este interrogante es negativa, ya que para Kant la relación entre los sexos es una relación de dominación, una relación en las que las mujeres quieren dominar y los hombres ser dominados. Y es esta tensión o guerra de los sexos lo que dota de significado al respeto por las mujeres, ya que "las mujeres exigen consideración, en nombre del verdadero nombre de su sexo, incluso si no son merecedoras del mismo - esto es lo que significa respeto" (2007, p. 190).

En consonancia no casual con Rousseau Kant atribuye a las mujeres la modestia como característica natural. $\mathrm{Y}$ es esta modestia la que las hace respetables, pues por la misma educan al hombre y lo hacen moral: “Al mismo tiempo que ella satisface su deseo de dominar, al educar al hombre en la castidad lo educa en la moralidad" (Kofman, 2007, p. 190). De esta manera, interpreta Kofman, el respeto por las mujeres es condición para el auténtico respeto: el respeto por la ley moral. A partir de ese primer signo de su capacidad moral, que es el respeto por las mujeres, el hombre puede ascender de la animalidad y la sensualidad a la moralidad y, con ello, al estado de civilización. Este ascenso “está descrito como separación de la madre, del pecho materno de la naturaleza, que el hombre a través de su imaginación se representa retrospectivamente como un paraíso" (Kofman, 2007, p. 193). Y sólo por esa separación de la madre, de la naturaleza, de la mujer, el hombre puede entrar en el más elevado reino de la moral. Tiene que sortear el riesgo de quedar prendido de lo femenino, de los sentimientos frente a la razón, de 
"perder la dignidad como hombre, al perder la virilidad, retornando en un camino regresivo al pecho de la Madre Naturaleza" (Kofman, 2007, p. 194).

Para la psicoanalista la atracción nostálgica por la madre, por el "pecho materno" como paraíso perdido, lleva a Kant a la vez a la fascinación y a la repulsión, a una ambigüedad que se resuelve en el imaginario de una doble proyección: "la de la sensualidad, cargada de todo el mal, una imagen repugnante y desagradable; la de la santa ley, sublime, heredera del poder y la majestad de la figura originalmente fascinadora" (Kofman, 2007, p. 196). Kofman interpreta que hay aquí una "grandiosa sublimación" de la figura de la madre, al modo como en Freud el respeto por la madre, normativizado por la ley del incesto, da origen a esa figura femenina dual: por un lado, la prostituta, "objeto sexual degradado con el que el hombre puede satisfacer su sensualidad"; y, por otro, "la de la figura sublime y eminentemente respetable, elevada a un pedestal de santidad, la inmaculada e intocable Virgen" (2007, p. 196). Por tanto, si el respeto por las mujeres es en primera instancia y esencialmente el respeto por la madre en los hombres, la condición del respeto moral no será otra que la prohibición del incesto. Pero si esto es así, razona Kofman, estaríamos ante un origen empírico del respeto por la ley moral y no, como Kant lo pretende, ante la relación a priori del hombre con la ley y el sentimiento moral.

Por supuesto, Kofman tiene perfectamente claro que Kant no podría admitir que con la idea de ley moral estemos ante una sublimación de la figura de la madre, ya que no podría aceptar que los principios morales que teoriza como a priori se puedan reducir a una representación empírica o a posteriori. Si aceptamos que el respeto moral empieza por el respeto por las mujeres y, con ello, por la prohibición del incesto, estaríamos aceptando la contaminación de la ley moral por lo empírico. Esto sería tanto como "desenmascarar la ley", lo que "sería quizá hacerse consciente de que su autoridad no emana pura y simplemente de su carácter a priori; de que lo a priori está ya siempre contaminado por lo a posteriori, lo masculino por lo femenino". En otras palabras, sería conceder que la moral pura es tan sólo "el fantasma de todos los niños, el sueño de toda la filosofía" (Kofman, 2007, p. 201). 
Ahora bien, la concepción moral kantiana, que tiene que separarse de la madre y de la feminidad en tanto viene a identificar logos y falo, tiene un coste psíquico que no es otro que el de perder todo placer sensual. Para Kofman esta pérdida supone verse embarcado en "la neurosis y la miseria, excepto para aquellos capaces de procurarse a sí mismos la sustitución de las satisfacciones por la vía de la sublimación" (2007, p. 202). La madre en Kant, en tanto relación originaria, es para Kofman puesta por Kant fuera de escena a partir de la sublimación en una relación a priori de respeto por la ley moral que quiere desactivar toda contaminación de lo femenino.

Esta lectura que Kofman hace del pensamiento kantiano, y también del rousseauniano, sobre lo femenino está guiada por el psicoanálisis y, más concretamente, por las elaboraciones de Freud acerca de la mujer y la madre. Desde ahí, Kofman quiere desvelar cómo en Kant la relación originaria con la madre es puesta fuera de escena y sublimada en virtud de una relación a priori con el respeto por la ley moral que trasciende toda intimidad con lo femenino. De modo que el respeto por las mujeres en Kant concluye Kofman, no es otra cosa que "el reverso moral de la «misoginia» de los hombres" (2007, p. 201).

\section{2. ¿CON FREUD O CONTRA FREUD?}

\subsection{Sobre la sexualidad femenina en Freud}

Pero Sarah Kofman va a ir más allá de Kant o Rousseau y va a exponer su crítica a las tesis freudianas sobre la feminidad, en un ejercicio que, en tanto que psicoanalista freudiana, tiene mucho de autocrítica. Parte de que "Las feministas se declararían en guerra en contra de sus textos que estarían, en lo que toca a las mujeres, repletos de prejuicios masculinos" (Kofman, 1982, p. 25). De la lectura que esta pensadora hace de Freud se infiere que el analista habla antes de una idea de mujer, derivada de sus propios débitos con el pensamiento de la tradición patriarcal, que de las mujeres materiales y concretas.

Si "la mujer, por su sexo, sólo puede conllevar la ruina del hombre", el descubrimiento del sexo de la mujer, de la madre, determina el Edipo, por el 
que tomar el lugar del padre y acceder a la sexualidad con la madre. Kofman afirma que Freud lo que ha hecho es "exhibir a plena luz, junto con sus relaciones incestuosas criminales, el sexo de la mujer, de la madre" (1982, p. 44). Aun cuando Freud descubre y habla del momento preedípico, lo cierto es que en sus análisis todo el desarrollo sexual infantil se supedita al Edipo, cosa que le valió las críticas de seguidoras psicoanalistas como Melanie Klein, para quien hay que abandonar el Edipo como referente hegemónico de la evolución sexual y venir más bien a subordinarlo a lo preedípico. Sin embargo, subraya Kofman, en Freud esta reinterpretación es impensable, ya que "El modelo heroico de Freud sigue siendo el Edipo y la mujer no es jamás para él la novia sino y sobre todo la madre" (1982, p. 49).

La sexualidad femenina como objeto de estudio diferenciado no aparecerá en Freud hasta textos tardíos (1976 a) y ello puede explicarse porque "la sexualidad de la mujer continúa recubierta con un espeso velo" (Kofman, 1982, p. 53), que la hace opaca a la ciencia. Ese "velo", como recubrimiento del pudor femenino, hace de la mujer un enigma que el analista tendrá que desvelar. Y pretende hacerlo dándole la palabra, pero, al hacerlo, vuelve a subordinar esa palabra al discurso de la heterodesignación, en este caso, la del propio psicoanalista ya que

“el remedio que les propone es al mismo tiempo un veneno porque no puede curarlas sino es contaminándolas, forzándolas a «colaborar», a aceptar el punto de vista del otro, del hombre que considera poseer la verdad. La solución psicoanalítica devuelve a la mujer su palabra para quitársela mejor, para subordinarla mejor a la del señor" (Kofman, 1982, p. 62).

Ahora la mujer ha de convencerse de ser una "enferma" que requiere del analista-varón para su curación" (Kofman, 1982, p. 81).

En su conferencia sobre La femineidad(1976 b), Freud habla del pudor femenino en una doble dimensión: por un lado, es algo devenido de la cultura de la represión sexual, pero, por otro lado, es algo natural encarnado en el vello púbico que sirve para evitar el horror que puede producir en los hombres el 
órgano genital femenino, ya que este "puede excitar, encantar a los hombres, que de lo contrario retrocederían horrorizados frente a este agujero infectado que podría contaminarlos y se verían condenados a la homosexualidad" (Kofman, 1982, pp. 63-64). Esta tesis del pudor como artificio de la naturaleza para que los hombres, puedan penetrar el sexo femenino a pesar de su defectuosidad y, con ello, asegurar la reproducción de la especie, no parece por cierto tan alejada de las afirmaciones rousseaunianas sobre el pudor femenino como finalidad natural.

También como "artimaña de la naturaleza" es entendida en Freud la transferencia que hace que la mujer narcisista pueda amar objetualmente, pueda amar a otro, pero "a condición de que represente una parte de su propio yo o de lo que ella ha sido en otro tiempo" (Kofman, 1982, p. 72). Kofman analiza cómo para Freud este tipo de mujer, la narcisista es la más común, aquella que se ama a sí misma, que no es capaz de satisfacer al enamorado y que sólo ama ser amada. De nuevo, interviene la naturaleza para que, por medio del embarazo, esta mujer pueda proyectar su narcisismo hacia el hijo/a como parte de sí misma.

En una línea muy kantiana, Freud va a situar a la mujer como" sexo fuerte", en tanto en cuanto el hombre siempre siente temor a ser contaminado y emasculado por la femineidad. La vía para invertir ese dominio femenino pasará por hacer de la sexualidad femenina algo siempre incompleto, esa falta de pene que provoca la consiguiente envidia y el resentimiento femeninos Se trata de dar la vuelta a la fantasía infantil de la madre fálica, leyendo ahora el deseo como orientado a pasar de la madre al padre o, lo que es lo mismo, al pasaje a la razón y la civilización. Porque este pasaje es paralelo al pasaje de la humanidad del estado del mito al del logos, al saber psicoanalítico:

“Freud coloca primero la anticipación para dominarla mejor: el mito conoce bien, pero sólo de manera balbuceante, infantil, confusa, en imágenes, oscura, inarticulada, inconsciente, y debe ser recompuesto por y en la claridad del saber analítico adulto para que la Verdad acceda a hablar con propiedad: el mito detenta la verdad en potencia, pero esta potencia mítica sólo adquiere sentido gracias al pasaje al acto 
mediante la formulación de la ciencia psicoanalítica" (Kofman,1982, p. 93).

Al igual que el logos corta con el estadio originario del mito, el hijo corta el cordón umbilical con la madre y se abre al pasaje de la verdad que no es otra que la que formula la ciencia psicoanalítica.

Que la madre no tiene pene provoca en el hijo la angustia de la propia castración y es, así, la génesis de la necesidad de cortar el cordón umbilical con la misma, de "matarla": "El horror nunca está provocado simplemente por la castración del otro, de la madre, siempre es también angustia de castración por sí mismo" (Kofman, 1982, p. 100). Esta angustia de castración tiene que ser superada para que el hombre pueda mantener relaciones heterosexuales, como sucede en la mayoría de los casos, y no relaciones homosexuales como a las que le predispondría ese horror por la propia castración. Y la superación viene por el reconocimiento de la carencia materna del pene, ya que "es como si el padre hubiera castrado a la mujer y le hubiera dado al hijo el falo de la madre, a manera de «columna suplementaria»" (Kofman, 1982, p. 105). De manera que, concluye Kofman, la consabida envidia del pene de la mujer es, a la vez, aceptación de la superioridad fálica del hombre, con lo cual "Freud se las arregla para que la mujer se rebaje a sí misma, rebaje a su madre y a todas las mujeres" (1982, p. 109).

Kofman afirma que "Freud amaba demasiado a su madre, esta fuente de vida y verdad, para correr el riesgo de matarla". Y "matarla" implicaba resolver “«verdaderamente» al enigma de la sexualidad femenina" (1982, p. 111). Por ello, Freud más que resolver ese enigma, lo que habría hecho es resguardarlo como paradigma de todo enigma. Sí resulta posible, sin embargo, tomando la vía psicoanalítica, analizar la diferenciación de los sexos "a partir de una bisexualidad originaria" (Kofman, 1982, 139). Ahora bien, Kofman plantea la sospecha crítica de que esa bisexualidad no siga siendo una estrategia para "a la vez disolver la oposición metafísica de una masculinidad y una feminidad «puras» y seguir manteniendo lo masculino con todos sus privilegios tradicionales" (1982, p. 140). Si la niña en Freud tiene que pasar del clítoris a la 
vagina como zona erógena en su evolución sexual, el niño va a mantener durante toda su vida sexual la misma zona erógena. Y ello hace que el pene venga a constituirse en "la zona erógena directora para los dos sexos" (Kofman, 1982, p. 152). De hecho, el clítoris no es otra cosa que un pene pequeño y puesto que la niña tiene un pequeñísimo pene es simplemente "un pequeñísimo hombre, un hombre menor" (Kofman, 1982, p. 156).

El descubrimiento del pene de mayor tamaño del hermano lleva a la niña a envidiar aquello de lo que su propio órgano no sería más que un simulacro. Pero Kofman vuelve a practicar aquí la filosofía de la sospecha y plantea si no es necesario que la niña se haya sentido inferiorizada por otras razones en primer lugar para que, en segundo lugar y como consecuencia, la diferencia de tamaño venga a redundar en la infravaloración de su propio órgano sexual:

“¿Puede ser que el valor o la falta de valor que la niña concede a su propio sexo provenga de una simple diferencia de «talla»? ¿No es necesario que la niña ya se haya sentido - por múltiples razones«inferior», para utilizar así, como un pretexto, una diferencia de tamaño para «envidiar» tan brutal y definitivamente al varón? Y, además, ¿quién establece aquí entre niña y niño, entre clítoris y pene, una simple diferencia cuantitativa? ¿El niño? ¿La ciencia? ¿Freud?” (1982, p. 158).

En su desarrollo sexual, la niña, para pasar a ser mujer, tendrá que realizar en Freud la transferencia del objeto de deseo de la madre al padre y, para que esta transferencia pueda llevarse a cabo, el amor originario de la niña por la madre pasará a ser odio, un odio que se explica porque la niña reprocha a la madre que no le haya dado "un «verdadero» órgano genital, el haberla hecho nacer niña y no varón" (Kofman, 1982, p. 189). Convertida, pues, la envidia del pene en la constante de la sexualidad femenina, Kofman afirma que "el resto de la vida de la niña, de la mujer, puede decirse que es un conjunto de tentativas, más o menos fantaseadas, para intentar, a pesar de todo, satisfacer esta irrazonable, y sin embargo necesaria envidia" (1982, p. 195)

Pero Kofman critica que esta solución freudiana a la impronta de la sexualidad femenina es en realidad algo "delirante" y, en el caso de existir, no puede interpretarse como un fenómeno primario, sino en todo caso como derivado de 
una vivencia anterior de su inferioridad: “¿No es preciso que la niña se haya sentido anteriormente «inferior» para que se aferre a una inferioridad de órgano como de un pretexto para renunciar a su placer y al amor materno?" (1982, p. 204). Kofman argumenta además que, antes de rechazar a la madre por no tener pene y no habérselo dado a ella, la niña cree que la madre, y ella misma, son portadoras de un pene. Por tanto, si esto es así, cuando descubre el pene del varón no tiene por qué vivirlo como carencia propia, sino antes bien como "réplica" del que cree suyo. En realidad, asevera Kofman, aunque Freud hace ver que concede una relevancia decisiva al momento preedípico y al vínculo con la madre, lo cierto es que "detrás del objeto madre, tanto como del objeto padre, lo deseado sería siempre el pene", con lo que Freud "se las arregla para hacer del órgano masculino el agente director del comportamiento de la niña, y para someter su evolución sexual únicamente a la envidia del pene" (1982, pp. 207-208).

Instituir la femineidad pasa por la renuncia de la niña a la actividad masturbadora clitoriana y, con ello, por la resignación a la pasividad sexual. El advenimiento del Edipo supone para la niña reprimir la actividad auto-erógena, odiar a la madre y orientar el objeto de deseo al padre. Pero si el deseo de poseer un pene marca todo el desarrollo sexual femenino, Kofman plantea: “Pero ¿qué ocurre con el deseo del varón? ¿Es de una esencia diferente?” (1982, p. 213). Freud pretende que el deseo femenino y el masculino no son esencialmente diferentes, pero Kofman opone el sentido excesivo, patológico, de la envidia femenina:

"es como si el carácter «reactivo», el resentimiento, la envidia, se atribuyeran solamente a las mujeres, al menos en su carácter «excesivo», es decir patológico. Entre el deseo de la niña y el del varón la diferencia es simplemente gradual, la que va de lo patológico a lo normal: para los dos sexos el deseo por naturaleza es una carencia infinita, avidez que nada podría calmar. Sin embargo, en el seno de este infinito, podríamos distinguir una mayor y una menor carencia, responsable de la diferencia de los sexos - una mayor carencia por la falta de pene sería el origen de la excesiva envidia de la niña" (Kofman,1982, pp. 213-214). 
De nuevo la naturaleza viene en ayuda de la teorización del psicoanalista y la envidia del pene femenina da paso al deseo del hijo. Así la maternidad es interpretada como el deseo de la mujer de tener un pene, con ocasión de desear el niño como sustituto del pene. Pero si es así, razona Kofman, lo que orienta la maternidad femenina es de nuevo la envidia del pene, el deseo de poseer un pene que se calma en la correspondencia simbólica entre el pene y el niño-varón portador del mismo: "El niño-pene portador en sí mismo de pene, a saber, un varón, es el único que podría «traer consigo el pene deseado»" (1982, p. 216). El deseo de la niña de obtener un pene explica que ésta pase al momento edípico al hacer del padre ahora su objeto de amor. En el Edipo la diferencia fundamental entre el niño y la niña radica en que en el primero se da una «simple amenaza de castración», mientras en la segunda lo que hay es la vivencia de una «castración realizada». Esta diferencia no es inocua, pues en Freud se traduce en una diferente formación del superyó, que tiene como resultado que haya diferencias morales entre el hombre y la mujer. Kofman se irrita con su maestro y denuncia el substrato ideológico-patriarcal que lleva a justificar la inferiorización moral y cultural de la mujer como orden natural:

“atribuir a una diferencia de destino del complejo de Edipo la diferencia moral y cultural del hombre y de la mujer, es justificar, en nombre de la naturaleza, la represión cultural de la mujer, es legitimar todas las desigualdades culturales y sociales apelando a una evolución de la libido que, como es larga y penosa en la mujer, la obligaría a rezagarse, como Ulises con la maga Circe, en ese puerto que es el Edipo, al punto de superarlo sólo «tardíamente y de manera incompleta», demasiado tardíamente, en cualquier caso, para que resulte bien, para que la formación del superyó, y por lo tanto la moral y la cultura de la mujer, no se vean definitivamente comprometidas" (Kofman, 1982, p. 224).

\subsection{Crítica al concepto de feminidad en Freud}

Esta lectura crítica de Kofman nos evoca, irremediablemente, su propia impugnación del pensamiento rousseauniano y del kantiano sobre lo femenino 
como inferior por orden de naturaleza. En Freud tal remisión a lo natural se reviste además de determinación psico-sexual debido a la femenina envidia del pene. Ahora bien, qué ocurriría si la niña no responde con esa envidia al descubrir el pene masculino, es algo que Freud contempla no como una refutación, sino como una corroboración de su tesis: si la niña no reacciona con esa envidia es porque, al conceder precisamente un valor predominante al pene, ella tendrá la fantasía de poseer uno o de llegar a poseerlo. Y de ahí se produce la homosexualidad femenina, en la que Freud interpreta que

"la elección de objeto homosexual que caracteriza frecuentemente este tipo de mujer es considerada no como el deseo de una mujer por otra mujer, sino como el deseo de un hombre por otro hombre (por una mujer que se piensa, a su imagen, portadora de pene porque ella misma se identifica con la madre fálica o el padre)" (Kofman, 1982, pp. 226227).

Por tanto, estos casos no refutan para Freud su interpretación, porque cuando este tipo de mujer rechaza su sexualidad como carencia de pene lo que en realidad ocurre es que "una mujer se cree un hombre cuando ella es, de hecho, (casi) un hombre" (Kofman, 1982, p. 228).

Freud entiende que la subordinación femenina es algo cultural y que se ve reforzada en el matrimonio monógamo. Que la mujer participe de los deseos del hombre "es lo único que impide que la «agresión» sexual masculina sea una violación y una violencia perpetuas" (Kofman, 1982, p. 232). Pero, si la mujer se muestra hostil y manifiesta una frigidez frente a los estímulos sexuales de su marido, el psicoanalista interpreta que ello no tiene nada que ver con su resistencia al estado de sometimiento, sino con que, a causa de la desfloración, padece una herida narcisista que redobla de manera más profunda la inevitable envidia del pene.

En la conferencia sobre La Femineidad de 1932 el desarrollo de la sexualidad femenina, hasta aquí considerado, se va a traducir en las "particularidades" propias de la mujer en la madurez. Determinadas por la envidia del pene - que "parece que ha sido concebida, en última instancia, como natural, demasiado 
natural puesto que sería ese «hecho biológico» insuperable, esa roca que se encontraría bajo todos los estratos" (Kofman, 1982, p. 235) - esas "particularidades" expresan el narcisismo de la mujer, que sólo se ama a sí misma. Por ello, la vanidad será su característica principal, que intenta compensar la falla de su órgano genital y que le va a llevar a usar la belleza como "una trampa superpuesta a la de la naturaleza, para recubrir la fealdad de esos órganos sexuales incompletos" y, de esta manera "seducir, a pesar de todo, a los hombres" (Kofman, 1982, 236). Otra particularidad femenina será el ser hostil a la madre y volverse al padre y, con ello, al hombre, ya que "puede darle el hijo por el cual la madre obtiene una satisfacción completa: todas las religiones han sabido que es el Niño el que salva a la madre, el que le permite levantar la cabeza, curar su herida narcisista". Y cura su herida narcisista, ya que "si ella no es un hombre al menos ha echado al mundo un pequeño hombre al que ama como a una parte de sí misma, una parte más preciada cuanto testimonia, a pesar de todo, su «propia» virilidad" (Kofman, 1982, p. 239). Esta particularidad hace que la mujer quiera encerrarse en la familia, mostrando "actitud hostil hacia la civilización", en tanto en cuanto esta le priva de su marido y de su hijo. Pues el hombre, que a diferencia de la mujer sí sublima sus pulsiones sexuales, trasciende la «sociedad cerrada», esto es la familia, y se abre a la esfera pública, a la «sociedad abierta». Encerrada sobre sí misma, enclavada en la familia, incapaz de amar a la humanidad y, por tanto, esclava de las pulsiones de muerte, Kofman subraya cómo en Freud "la inferioridad social de la mujer, su falta de «aptitud» para la sublimación son declaradas innatas e indelebles, consideradas caracteres naturales e imborrables" (Kofman, 1982, p. 244).

Las particularidades femeninas no son pensadas en Freud como fluidas o flexibles, sino que antes bien las pretende fijadas e inamovibles a la edad de treinta años, de tal manera que aquí se detiene y se reifica ese eterno femenino que ya no va a ser susceptible de cambios: "no podemos dejar de pensar que esta «cosificación» de las mujeres corresponde a un deseo profundo de Freud de fijarlas en un «eterno femenino» que ningún progreso social podría transformar, aunque esto cueste muy caro a las mujeres" (Kofman, 1982, p. 246). Kofman subraya que esta lectura freudiana de la naturaleza femenina la 
convierte en un cadáver, anulando en ella toda pulsión del Eros y resolviendo el enigma femenino en "la detención mortífera" de la mujer". De modo que el discurso psicoanalítico

"sólo tocó a la mujer para cadaverizarla (...) Porque la rigidez cadavérica sirve para mantener reprimida la «masculinidad» femenina, permite anular el perpetuo balanceo entre lo masculino y lo femenino que constituye todo el enigma de la «mujer». Es decir que la mujer, llegada a la madurez, la mujer de treinta años, no podría ser plenamente mujer más que al precio de la muerte - al precio del triunfo en ella de la «femineidad»sobre la «masculinidad», o sea, al parecer, de las pulsiones de muerte sobre el Eros" (Kofman, 1982, p. 248).

Por último, y aunque para el tema que nos ocupa no se trata de hacer un recorrido por las relaciones entre psicoanálisis y feminismo, quizá convenga apunta brevemente que el feminismo ha enfrentado el psicoanálisis críticamente, aunque no ha dejado de relacionarse con él. Así, en los años 60 del siglo pasado, el feminismo desveló su carácter radicalmente patriarcal, como hizo ya Kate Millett en su Política sexual en 1970 (2010). Cuatro años después, desde una posición crítica, Juliet Mitchell (1976), en su ya clásico ensayo sobre Psicoanálisis y feminismo, argumenta que el feminismo no debe rechazar el psicoanálisis, entendiendo que este no es una justificación del sistema patriarcal, sino un análisis del mismo. Entre lo años 70 y 80 se realizan lecturas feministas, que abundan en la fase pre-edípica y en la figura determinante de la madre para las relaciones intersubjetivas, línea esta en la que destacan Nancy Chodorow (1984) y Jessica Benjamin (1988). Estas psicoanlistas feministas cuestionan la suposición freudianada de que la genitalidad masculina guía el desarrollo del deseo sexual y en particular Benjamin,discute el complejo de Edipo y propone releerlo desde claves no patriarcales.

Por su parte, el llamado feminismo de la diferencia hace pie en el psicoanálisis, pero preferentemente el lacaniano: así en el caso de la francesa Luce Irigaray (2009), como en el caso de la italina Luisa Muraro (1994). Desde su radical oposición a la idea de la mujer como castrada y a la consecuente envidia del pene, Irigaray critica ya a finales de los años 70 a Freud y también a Lacan, lo 
que le valió su expulsión del círculo psicoanalítico lacanianano. Pero las pensadoras de la diferencia van a utilizar las herramientas del psicoanálisis lacaniano para analizar cómo lo femenino ha sido excluído del orden simbólico masculino, conceptualizado como lo diferente o lo no-idéntico.

Hoy sigue habiendo mujeres que trabajan en conjugar psicoanálisis y feminismo a partir de los años 90, como es el caso de Emilce Dio Bleichmar, por quedarnos aquí tan sólo con un ejemplo. Bleichmar sigue reflexionando sobre la posibilidad de pensar lo femenino y lo masculino sin el complejo de Edipo como referente principal. En este sentido sostiene, entre otras cosas, que la identidad de género se produce antes de la elección del objeto sexual (Bleichmar, 1996).

Seguir indagando las relaciones entre los discursos feminista y psicoanalítico nos llevaría mucho más allá de lo que este trabajo se propone. Que, además de la relación conflictiva entre ambos, pueda hablarse de que el feminism se enriquece con las aportaciones del psicoanálisis, es algo que también han querido dejar claro algunas feministas actuales. Así se ha afirmado que "el psicoanálisis -leído a través de Freud y de algunas aportaciones de Lacan- en cuanto construcción teórica ofrece a la reflexión sobre la desigualdad sexual una importante vía de acceso para un tratamiento pertinente del problema de la mujer, entre otras cosas porque, como veremos, permite desplazar la cuestión sobre la constitución de los sujetos del plano de lo biológico al de lo cultural" (Serret, 1989).

Dejaremos aquí apuntadas estas líneas sobre cómo, tras Sarah Kofman, se han configurado algunos discursos feministas en su intersección con el psicoanálisis, subrayando tan solo que la crítica al modelo de Edipo, en tanto que creación histórica patriarchal, así como a la concepción de la sexualidad femenina y al lugar de la mujer en el psicoanálisis estaba ya en explicitada en su propio pensamiento, como hemos tratado de mostrar aquí. 


\section{BREVES CONCLUSIONES}

Dejaremos aquí apuntadas estas líneas sobre cómo, tras Sarah Kofman, se han configurado algunos discursos feministas en su intersección con el psicoanálisis, subrayando tan solo que la crítica al modelo de Edipo, en tanto que creación histórica patriarcal, así como a la concepción de la sexualidad femenina y al lugar de la mujer en el psicoanálisis estaba ya en explicitada en su propio pensamiento, como hemos tratado de mostrar aquí.

Una primera conclusión será que, situada en el marco psicoanalítico, la interpretación que hace Sarah Kofman de la femineidad en Freud toma derroteros que no están muy lejos de la perspectiva crítico-feminista. Sin embargo, su lectura no pretende impugnar el pensamiento freudiano, en cuya lógica se mantiene y dentro de la cual, como hemos tenido ocasión de ver, parece orientarse a refutar la tesis de la sexualidad femenina como determinada por la envidia del pene. Porque esta tesis, para Kofman, viene a legitimar las desigualdades culturales y sociales de la mujer y su inferiorización moral y psíquica.

Pero, como segunda conclusión, entendemos que, al contrario que en los análisis del pensamiento de Rousseau y de Kant sobre lo femenino como planteamiento falocráticos o regidos por la lógica patriarcal, en el caso de Freud Kofman parece inclinada a leer la envidia del pene como una particular obsesión del analista, cuyas consecuencias sobre la concepción de la femineidad no son, sin embargo, explotadas desde un discurso que implique un proyecto feminista de emancipación. Ni siquiera se analiza cómo la mujer queda excluida de una estructura propia de deseo y permanece orientada y determinada, por razón de naturaleza, a poseer o envidiar el órgano masculino, asimilándose así a lo masculino entendido como lo genéricamente humano.

Como última conclusión, que se deriva de las precedentes, podría subrayarse que Kofman no parece apercibirse de que la visión freudiana constituye, antes que un análisis descriptivo lastrado por una errónea interpretación de cómo es 
la femineidad, un auténtico discurso normativo de cómo esta debe ser. Cabe suscribir, por tanto, que en efecto

"hay que decir que Kofman no fue una pensadora feminista ni trabajó sobre autoras (...) Como dice Kofman, el tema de la «mujer» no es un «tema» que ella busque tratar: es más una huella que recorre en los sistemas filosóficos para detectar una especie de punto ciego, es decir, el lugar más débil del sistema y que aclara lo que verdaderamente está en juego" (Birulés, 2015, pp. 187-188).

Precisamente por ello creemos, concluyendo finalmente, que el pensamiento de Kofman es un lugar de interés para ser transitado por la tarea crítico-feminista.

\section{BIBLIOGRAFÍA}

Benjamin, J. (1988). The Bonds of Love: Psychoanalysis, Feminism and the Problem of Domination. New York: Pantheon Books.

Birulés, F. (20015). Entreactos. En torno a la política, el feminismo y el pensamiento. Buenos Aires -Madrid: Katz Editores.

Burgos Díaz, E. (2002). A propósito de la misoginia de Nietzsche. Revista Laguna, 10,133-153.

Chodorow, N. (1984). El ejercicio de la maternidad. Barcelona: Gedisa.

Dio Bleichmar, E.et al. (1996). Género, psicoanálisis y subjetividad. Buenos Aires: Paidós.

Edwin, S. (2002). "Impossible" professions: Sarah Kofman, witnessing and the social depth of trauma. En K. Oliver y S. Ewin, Between the psyche and the social (pp. 123-148). Boston Way, Lanham, Maryland: Rowman \& Littlefield Publishers, Inc.

Ender, E. (1993). Interview avec Sarah Kofman. Subvertir le philosophique ou pour un supplement de jouissance. Compar(a)ison. An International Journal of Comparative Literature, 1, 9-26.

Feyertag, K. (2014). Sarah Kofman. Eine Biographie. Viena-Berlín: Verlag Turia + Kant.

Freud, s. (1976 a). Sobre la sexualidad femenina. Obras Completas, vol. 21. Buenos Aires: Amorrortu Editores.

Freud, s. (1976 b). La feminidad. Obras Completas, vol. 22. Buenos Aires: Amorrortu Editores). 
Irigaray, L. (2009). Speculo. Espejo del otro sexo. Madrid: Ediciones Akal.

Kant, I. (1977). Anthropologie in pragmatischer Hinsicht. Weischedel (ed.), Werkausgabe Immanuel Kant. Werke in 12 Bänden, XII, 2. Frankfurt: Suhrkamp Verlag, 399-685.

Kofman, S. (1982). El Enigma de la mujer. ¿Con Freud o contra Freud? Barcelona: Gedisa, colección Psicoteca mayor Freudiana, 1982.

Kofman, S. (1986). Rousseau un die Frauen, Tübingen: Rive Gauche.

Kofman, S. (2007). The Economy of Respect: Kant and Respect for Women. En T. Albrecht (Ed.), Selected Writings by Sarah Kofman (pp. 187-202). Stanford: Stanford University Press.

Millett, K. (2010). Política Sexual. Madrid: Cátedra (Feminismos).

Rodgers, C. (1998). Sarah Kofman. En C. Rodgers (ed.), Le deuxième sexe de Simone de Beauvoir. Un héritage admiré et contesté (pp.165-186). Paris: l'Harmattan.

Mitchell, J. (1976). Psicoanálisis y feminismo. Barcelona: Anagrama.

Muraro, L. (1994). El orden simbólico de la madre. Madrid: horas y Horas.

Rousseau, J.-J. (1979). Emilio o de la educación. Barcelona: Editorial Bruguera.

Serret, Estela (1989). El sujeto femenino; para una refundamentación de la "teoría feminista". Sociológica, 4, (10). Disponible en http://www.sociologicamexico.azc.uam.mx/index.php/Sociologica/ar ticle/view/979 (consultado: 4-10-2018). 